\title{
Phenomenological issues related to strain localization in sensitive clays
}

\author{
VIKAS THAKUR ${ }^{\star}$, STEINAR NORDAL and GUSTAV GRIMSTAD \\ Geotechnical Division, Department of Civil and Transport Engineering, Norwegian University \\ of Science and Technology (NTNU), Hogskoleringen 7a, Gloshaugen, Trondheim, Norway, \\ NO 7491
}

(Received 22 April 2005; accepted 8 December 2005)

\begin{abstract}
A negative second order work, strain softening, is often noticed in contractant material like sensitive clays. Failure in such clays will lead to the formation of localized deformation zone of intense inelastic strain, known as shear band. Conditions, emergence and inclination of shear band has been very well demonstrated in past decades in different manners, however a definite thickness of shear band is still an open question due to several reasons. Mesh dependency, loss of ellipticity is another challenge associated with finite element analyses for strain softening clays. This paper covers a comprehensive review of classical theories of strain localization and associated limitation. Mesh dependency, ill-possed boundary value problem is addressed using finite element simulation examples and experimental results.
\end{abstract}

Key words. finite element analysis, localization theory, quick clay, shear band, strain softening.

\section{Introduction}

Some soils display a decrease in shear resistance with increasing strain from a peak value to an ultimate or residual value. This behaviour, recognized as strain softening or strain weakening, is very pronounced in soft and sensitive clays. Strain-softening behaviour may also be seen in stiff over consolidated clays (Bjerrum, 1967, Skempton, 1964). The general understanding is that stiff over consolidated soils tend to dilate and loose contracts, when sheared under drained conditions.

Strain localization theory was firstly proposed by Hadamard (1903), further, Hill's stability criteria (1962) and pioneering contribution from Thomas (1961), Mandel (1963), Rudnicki and Rice (1975), Rice (1976) and Vardoulakis (1980) helped in order to understand the localization theory. Several efforts have been made to describe the orientation and thickness of shear band in different geo-materials. Muhlhaus and Vardoulakis (1987) suggested criteria to measure the thickness of shear band in granular materials, which is 8 to 10 times of mean grain size; however a definite thickness of shear band in clay is still an open issue. On the other hand,

^ Vikas Thakur, Geotechnical Division, Department of Civil and Transport Engineering, Norwegian University of Science and Technology (NTNU), Hogskoleringen 7a, Gloshaugen, Trondheim, Norway, NO 7491. (tel.: 00477359 6871; fax: 00477359 4609; e-mail: vikas.thakur@ntnu.no) 
experimental observations from Morgenstern and Tschalenko (1967) and Vardoulakis (2002) suggested a factor of about 200 between the mean particle size and the shear band thickness, this conclusion was made based on dynamic-thermo-poro analysis for clays. It is widely accepted that clays have zero thickness of shear band eventually and it is better to specify as discontinuity, however, Bazant (1976) concluded the that strain softening will localize in to shear band of zero thickness, which would lead to no energy dissipation during failure, which means zero thickness of shear band is not a realistic interpretation.

Prediction of orientation of shear band, experimentally as well as numerically, has always been a challenging issue. Classical Coulomb solution, Roscoe solution (1970) or a numerical solution proposed by Arthur et al. (1977) has been varyingly accepted experimentally. Vardoulakis (1980), Desrus (1984) and a comprehensive review by Bardet (1990) show a distinct disagreement between any of these proposed classical solutions.

During the 1990s there has been several research workshops organized, in order to demonstrate the various methods of handling strain softening problems. Especially, regularization technique which gives a measure to obtain a definite thickness of shear band is mainly focused. Cosserat continuum theory (Cosserat and Cosserat, 1909), non local theory (Vermeer and Brinkgreve, 1994), second order strain gradient theory (Vardoulakis and Aifantis, 1991), visco plastic modelling (Oka et al., 1994), hypo plasticity (Gudehus, 1993, 1994, 2004) are some of the major contributions. However, most of these techniques are not suitable for soft and sensitive clays.

A very recent studies made by the author, Thakur et al. (2005) focus on importance of partial drainage during the shear banding in sensitive clays. It is believed soft and sensitive clays represents a rate dependent characteristics and hence coupled pore water strain localization analysis will be sufficient to capture a finite thickness of shear band. A comprehensive study by Thakur and Nordal (2005) on pore water pressure diffusion from shear band shows how local drainage can affect the shear band thickness. In order to combine clay skeleton viscosity, a elasto visco-plastic finite element program is developed by the author, Thakur and Jostad (2005) and used to calculate a definite thickness of shear band in soft clays.

This paper is mainly divided in two parts, first part covers the fundamental aspect of localization i.e. geo-materials stability criteria and standard strain localization theory based on bifurcation analysis, emergence of shear band due to singularity of acoustics tensor, ill posed boundary due to loss of ellipticity in governing equation and reviews the finite element analyses of deformation of strain softening material (Høeg, 1972; Rudnicki and Rice, 1975; Pietrusczak and Mroz, 1981). The second part emphasis on current research progress made in experimental investigation performed on highly sensitive clay i.e. Norwegian quick clay. In order to observe initial development of zones of concentrated shear strains, series of unconfined compression tests are performed. A particle tracking method is applied by means of a high resolution video camera to obtain a map of the sample surface strains during unconfined compression testing. 


\section{Strain Localization}

\subsection{STABILITY CRITERION}

There is no guarantee that an equilibrium state of a non linear system is stable. An equilibrium state is considered to be stable if the response of a vanishingly small disturbance also remains vanishingly small (Hill, 1959; Koiter, 1960; Jostad, 1993).

Sensitive clays mainly behave as softening material and hence this paper will only discuss about localization phenomenon under strain softening condition. Further, strain softening is possible either due to structural i.e. geometric instability or material instability. In common geotechnical engineering practice, structural i.e. geometric instability like buckling or snap through is ignored. However, fissuring, and cracking is always taken in account as material softening. On deriving constitutive model from experimental data, material softening needs to be isolated from geometrical softening otherwise such models would obtain an overdose of material softening (Vermeer and Brinkgreve, 1994).

Figure 1(a) shows the three well know different equilibrium condition; stable, unstable and neutral. It must be noted that, a same system can pass through all these equilibrium condition depending upon stress state and amount of energy dissipated i.e. state of second order work, refer Figure 1(b).
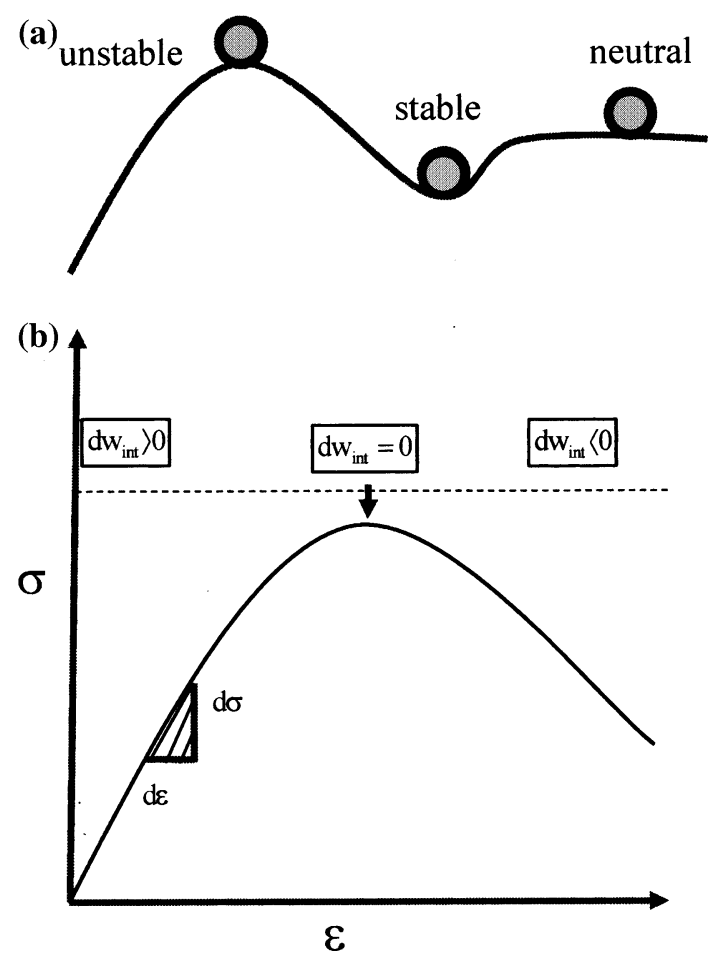

Figure 1. (a) Equilibrium conditions. (b) Stress $(\sigma)$-strain $(\varepsilon)$ response in softening material. 
Incremental internal energy based Hill's stability criteria (1959) is widely recognized and accepted to analyses the body undergoing through deformation (Jostad, 1993).

Incremental internal energy $\mathrm{d} W_{\text {int }}=\frac{1}{2} \int_{\mathrm{v}_{0}} \mathrm{~d} \sigma_{i j} \mathrm{~d} \varepsilon_{j i} \mathrm{~d} V$

Stable if $\mathrm{d} W_{\text {int }}>0$ for any $\mathbf{d x}$,

Unstable if $\mathrm{d} W_{\text {int }}<0$ for at least one $\mathbf{d x}$

Neutral if $\mathrm{d} W_{\text {int }}=0$ for at least one $\mathbf{d x}$ and remain stable for the rest

where, $\mathbf{d x}$ is incremental displacement

Here it is important to remember that Hill's stability criterion is necessary but not a guaranteed condition for stability. However, to have a guaranteed stability criterion, material must follow the constitutive condition.

$$
\mathrm{d} \sigma_{i j} \mathrm{~d} \varepsilon_{i j}=D_{i j k l} \mathrm{~d} \varepsilon_{k l} \mathrm{~d} \varepsilon_{i j} \geq 0
$$

where, $D_{i j k l}$ is tangential stiffness matrix.

In sensitive clays follows non associated flow rule and thus tangential stiffness matrix is very much influenced by angle of dilatancy $(\psi)$ and thus rate of softening is also function of angle of dilatancy. To demonstrate the affect of $\psi$, a 2 dimensional simple box subjected to pure shear is considered and simulated in finite element code, PLAXIS, as shown in Figure 2. Mohr-Coulomb model, elastic perfectly plastic model with negative dilatancy is considered. Sensitive clays are less permeable and hence analysis is made under undrained condition as pure frictional materal. A shear modulus (G) of $5000 \mathrm{kPa}$, poison's ratio (v) 0.25 and friction angle of 30 degree is considered.
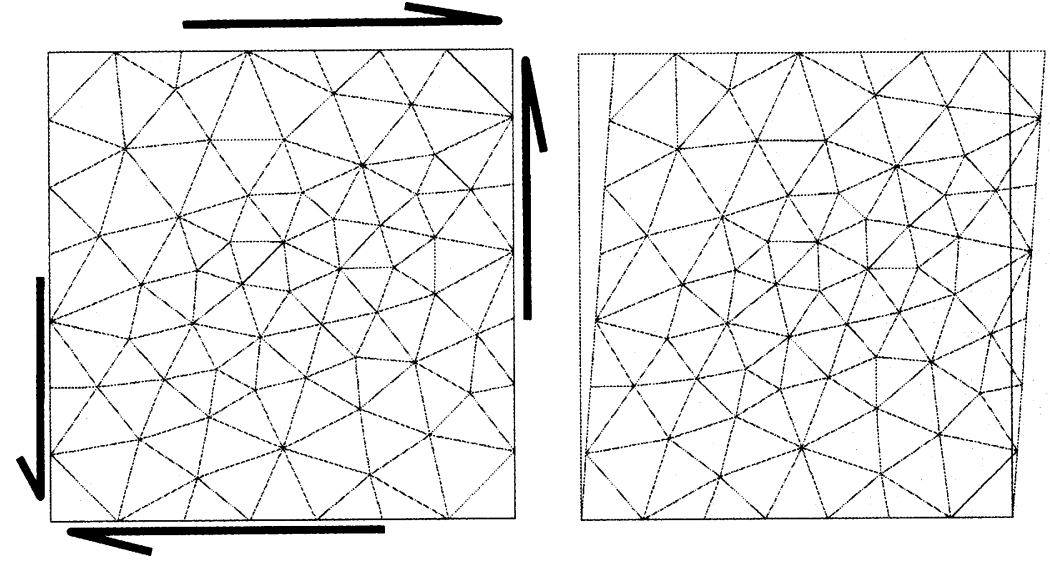

Figure 2. Box subjected to pure shear. 
$\sin \psi=-\frac{\mathrm{d}_{\varepsilon_{1}}+\mathrm{d}_{\varepsilon_{3}}}{\mathrm{~d}_{\varepsilon_{1}}-\mathrm{d}_{\varepsilon_{3}}}$, where negative sign of $\psi$ corresponds to contracting behaviour. Effective stress path and shear stress and shear strain response is presented in Figure 3. It can be seen that rate of softening is certainly a function of dilatency i.e. larger is the negative dilatency angle $(\psi)$, a higher strain softening rate can be observed.

Thakur et al. (2005) have proposed the equation to measure post peak pore pressure modulus.

$$
\frac{\mathrm{d} P w}{\mathrm{~d} \gamma}=\frac{G}{\left(\sin \phi+\frac{1-2 v}{\sin \psi}\right)}
$$

A finite element model is simulated to validate analytical equation (4). A higher pore pressure modulus represents a higher dilating behaviour i.e. contraction or dilation. It is found that proposed equation and finite element simulation is having quite significant match as shown in Figure 4.

\section{Localization Theory}

Strain localization theory can be well demonstrated by widely recognized bifurcation analysis.

\subsection{THE BIFURCATION ANALYSIS}

The bifurcation analysis is widely recognized theory for strain localization which specifies the condition for emergence of shear band within a homogeneous stress and strained media. Onset of localization, orientation of shear band and gradient of

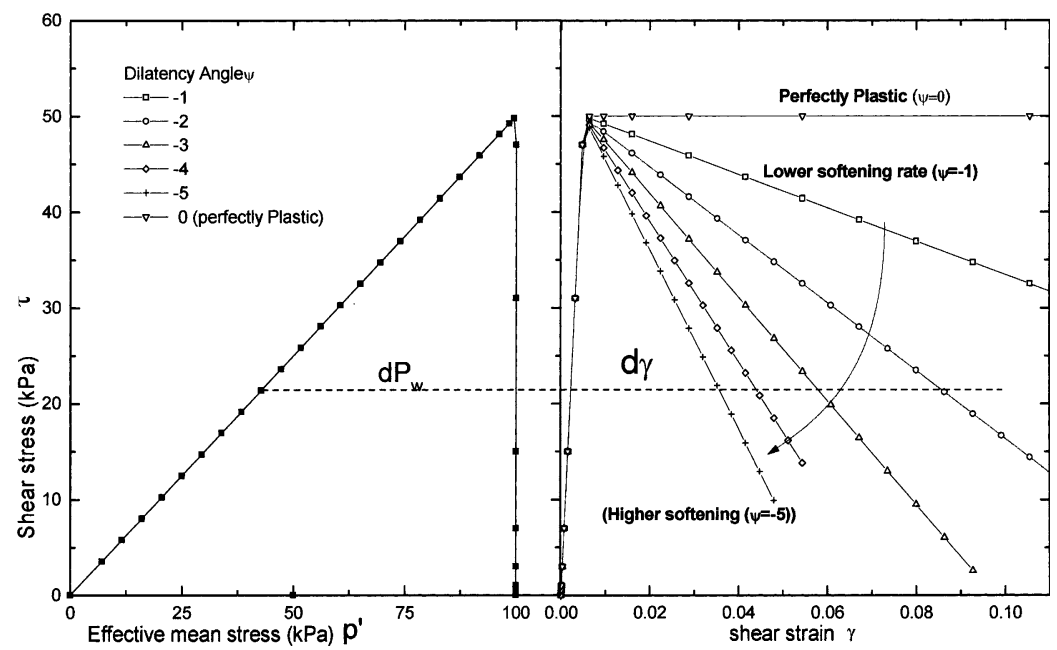

Figure 3. Effective stress path and stress strain behaviour. 


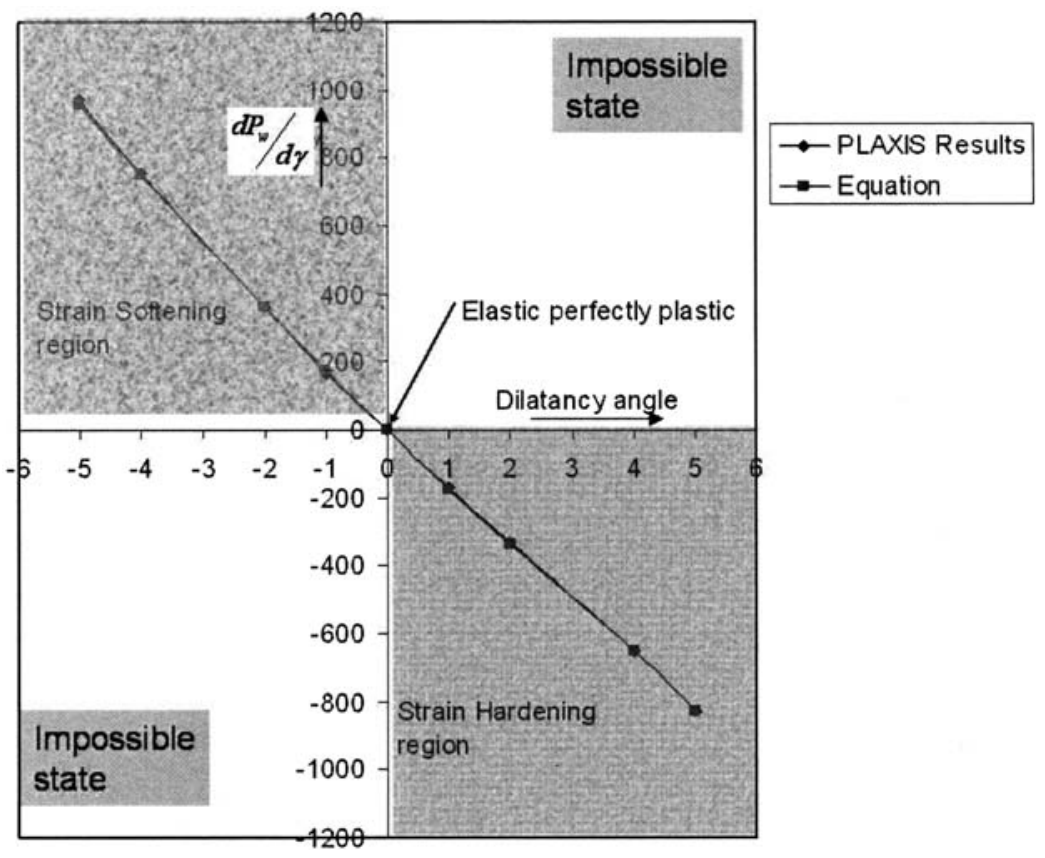

Figure 4. Validation of equation.

displacement rate can be obtained. However, this classical theory has three important limitation: first, theory analyses only the emergence of shear band but not its development, second there is no guarantee that shear band will actually emerge and last that thickness of shear band is left undetermined due to lack of internal length characteristics.

Shear band formation may be treated as a bifurcation problem within the framework of continuum mechanics. An infinite body subjected to uniform stress field may emerge a shear band under the localized deformation condition mentioned by Thomas (1961), Hill (1962), Mandel (1964), Rudniki and Rice (1975), Vardoulakis (1980) and Bardet (1990).

To describe kinematics of deformation, let us consider a body with a shear band of small thickness, tsb. Shear band is embedded between two singular surface $\Omega^{+}$and $\Omega^{-}$with a unit normal $\mathbf{n}$. The infinite body is subjected to uniform Cauchy stress $\boldsymbol{\sigma}$.

$$
L_{i j}=\frac{\partial v_{i}}{\partial x_{j}} \quad U_{i j}=\frac{1}{2}\left(L_{i j}+L_{j i}\right) \quad W_{i j}=\frac{1}{2}\left(L_{i j}-L_{j i}\right)
$$

where $v_{i}$, velocity; $L_{i j}$, velocity gradient and $U_{i j}, W_{i j}$ are deformation and spin tensor, respectively. As long as body is subjected to uniform deformation, $L_{i j}$ will remain same throughout body. But on set of localization, velocity gradient inside band, $L_{i j}{ }^{b}$, will no longer equal to $L_{i j}$ :

$$
L_{i j}^{b}=L_{i j}+\Delta L_{i j} \quad U_{i j}^{b}=U_{i j}+\Delta U_{i j} \quad W_{i j}^{b}=W_{i j}+\Delta W_{i j}
$$



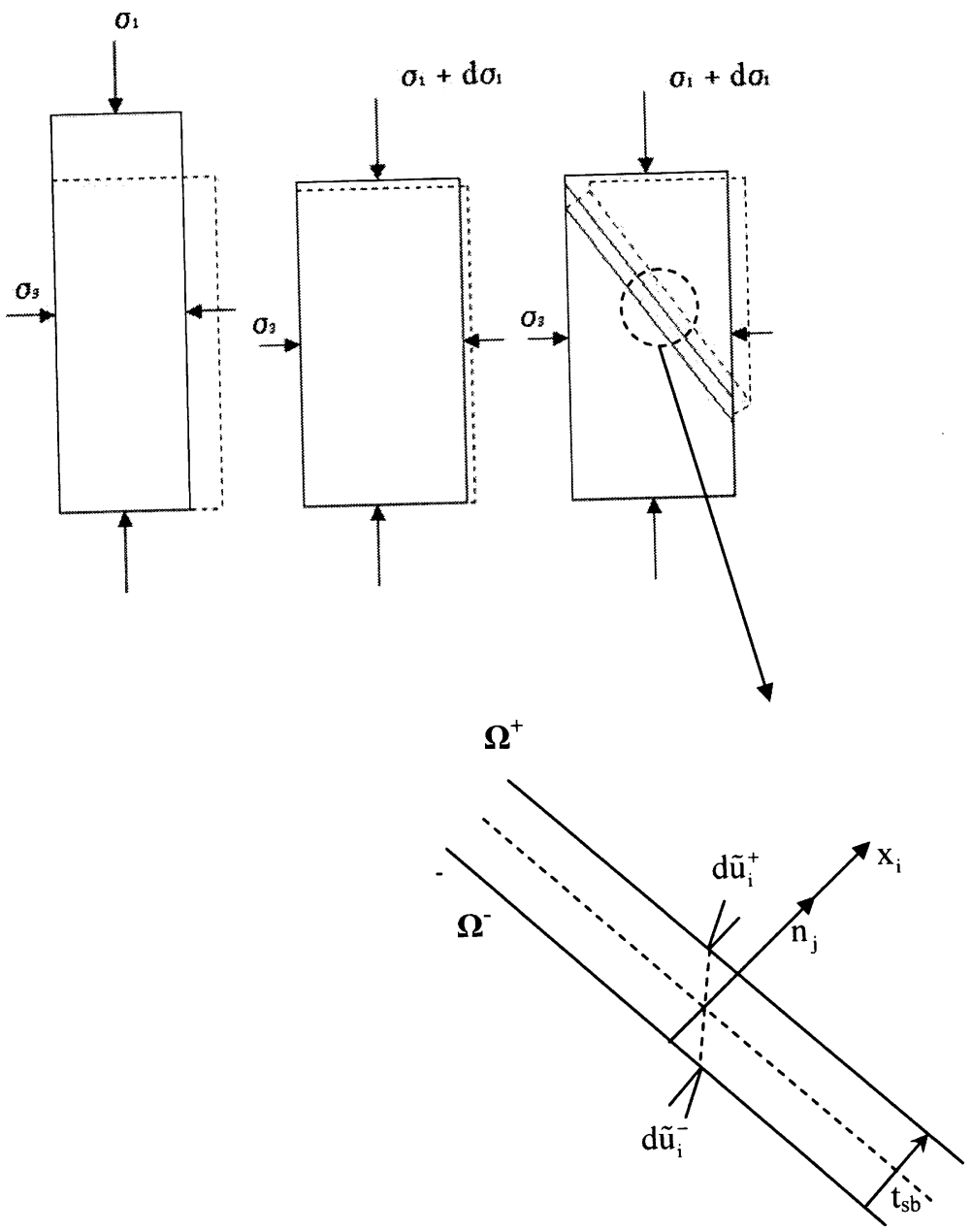

Figure 5. Schematic diagram of shear band.

where

$$
\Delta L_{i j}=x_{i} n_{j} \quad \Delta U_{i j}=\frac{1}{2}\left(n_{i} \cdot x_{j}+n_{j} \cdot x_{i}\right) \quad \Delta W_{i j}=\frac{1}{2}\left(x_{i} n_{j}-x_{j} n_{i}\right)
$$

$x_{j}$ is the component of a function $\mathbf{x}$ which depends on the distance across the band and vanishes outside the band. Assume, $\Omega^{-}$planer boundary is the datum line shear band. The deformation variation across the band can be written as:

$$
\mathrm{d} \tilde{u}_{i}=\left\{\begin{array}{cl}
\mathrm{d} \tilde{\mathrm{u}}_{i}^{+} & n_{j} x_{j}>t_{\mathrm{sb}}:\left(\text { region } \Omega^{+}\right) \\
\frac{1}{t_{\mathrm{sb}}} n_{j} x_{j}\left(\mathrm{~d} \tilde{\mathrm{u}}_{i}^{+}-\mathrm{d} \tilde{\mathrm{u}}_{i}^{-}\right) & 0 \leq n_{j} x_{j} \leq t_{\mathrm{sb}} \\
\mathrm{d} \tilde{\mathrm{u}}_{i}^{-} & n_{j} x_{j} \leq 0:\left(\text { region } \Omega^{-}\right)
\end{array}\right.
$$


The static incremental equilibrium condition, stress traction outside and inside band must be equal:

$$
\mathrm{dt}_{i}^{b}+\mathrm{dt}_{i}=0
$$

However, it must be noted that equation 9 gives an equilibrium condition in the direction of unit normal $\mathbf{n}$, but stresses along the shear band is not necessarily be equal and that may cause localization. Solution from Rudniki and Rice (1975), Bardet (1990) and Jostad (1993) proposed a constitutive law to fulfil for bifurcation condition. The possibility for the existence of a shear band to be when:

$$
\begin{aligned}
& \mathrm{d} \sigma_{i j}=D_{i j k l} \mathrm{~d} \varepsilon_{k l} \\
& \operatorname{det}\left(n_{j} \cdot D_{i j k l} \cdot n_{l}\right)=\operatorname{det} \mathrm{H}=0
\end{aligned}
$$

The expression $\mathbf{H}$ is denoted as acoustics tensor, whose vanishing determinant gives a necessary (but not sufficient) condition for emergence of shear band.

Classical continuum mechanics is not able to handle bifurcation problem related to strain softening. This is one of the reasons why finite element methods are not very much suitable to do complete analysis of shear band. Mesh dependent results can be obtained and always thickness of shear band depends on element size.

\subsection{LOSS OF ELLIPTICITY IN BOUNDARY VALUE PROBLEMS}

Static problems with close domain follows elliptic governing equation are commonly known as to boundary value problem (BVP) i.e. dependent variables are not specified at the same value of the independent variable. BVP becomes an ill-posed when it losses the ellipticity of the governing differential equation. Loss of uniqueness of the solution of such equations is not objective with respect to element descritization or mesh refinement. The total energy consumed by contracting process tends to zero as the elements are refined. In other words, loss of elipticity causes an ill posed boundary value problem, which gives rise to inherently non unique solutions in the form of arbitrarily narrow bands. Benallal et al. (1989) and de Brost et al. (1993) is presented a mathematical proof of loss of ellipticity when $\mathbf{H}$ vanishes, refer equation (10). It must be noted vanishing $\mathbf{H}$ causes a continuous bifurcation, which goes under deformation to a zero thickness of shear band.

As a consequences of ill posed boundary, finite element analyses suffer from Mesh dependency i.e. thickness of shear band, $t_{\mathrm{sb}}$, equals to size of one element. A finite element simulation of a vertical cut in sensitive clay is presented in Figure 6. Two different mesh density is chosen, 158 and 1380, refer Figure 6(a, b). A well defined failure pattern can be observed with descritization of mesh but the same time incremental shear strain is also localizing to one element. This example is repeated with several element sizes, each time shear band reduced to lowest element size. However, here only two extreme is presented i.e. a very coarse mesh and a very fine mesh. Finite element calculation automatically stops when shear band tends to localize less than one gauss integration material point. 

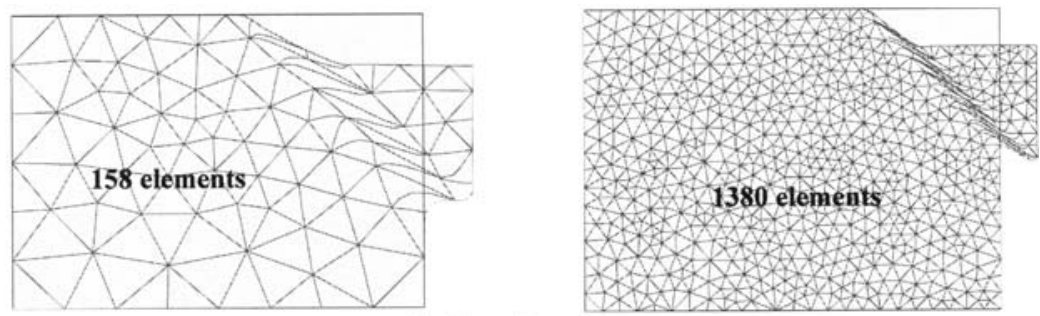

Deformed mesh

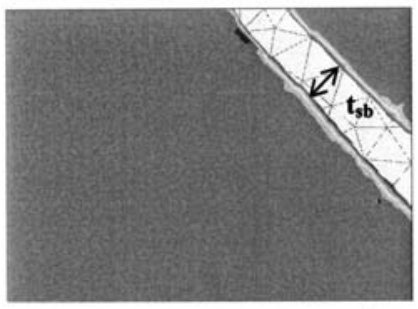

(a)

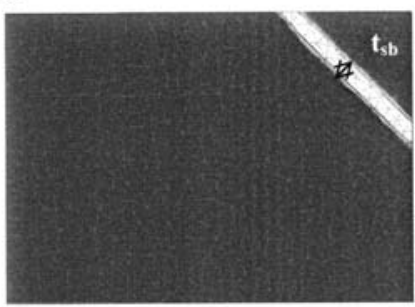

Incremental shear strain

(b)

Figure 6. Mesh dependent behaviour of sensitive clay.

Continuous localization behaviour can also be explained by energy principle. Let us consider a same infinite mass undergoing through a strain softening. Laboratory investigation shows that eventually, strain softening material goes to a residual shear strength value which depends on material sensitivity and strain rate. It is necessary to mentioned that obtained laboratory results are non local stress and strain relationship based on the fact that failure depend not only strain distribution inside the shear band but also outside elastically unloaded body too. However, finite element analyses are able to provide local stresses strain inside shear band. A contracting zone, $t_{\mathrm{sb}}$, will cause in increase in shear strain towards infinity. A stress strain curve for linear softening clay is plotted in Figure 7. However, this plot is simplified representation for a real behaviour of sensitive clay.

Assuming a one dimension strain softening case, work done inside shear band;

$$
\begin{aligned}
& \text { Workdone } \Rightarrow W=\int_{\nu} \int_{\gamma} \tau \cdot \mathrm{d} \gamma \cdot \mathrm{d} v \\
& W=B \cdot t_{\mathrm{sb}} \int_{\gamma} \tau \mathrm{d} \gamma \\
& W=B(\tilde{\tau} \cdot \delta)
\end{aligned}
$$

where,

$$
\tilde{\tau}=\left(\frac{1}{\gamma} \int_{\gamma} \tau \mathrm{d} \gamma\right)
$$




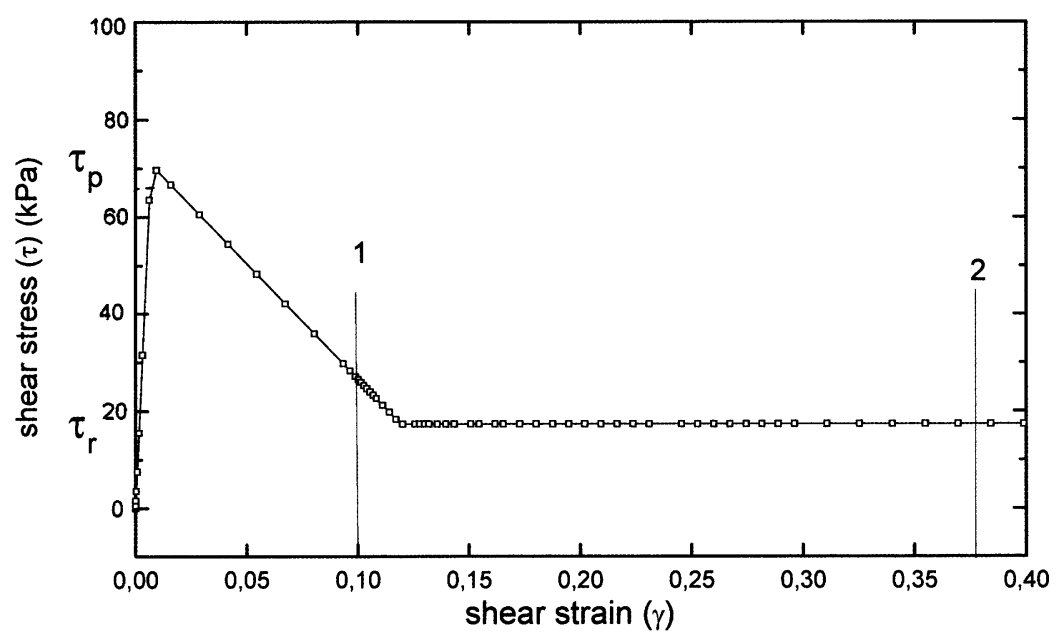

Figure 7. Linear softening stress strain curve.

The average shear stress $\tilde{\tau}$, is inversely proportional to shear strain, $\gamma$, which means higher shearing will reduce the total work done. In other words, two different stages of shearing, from 1 and 2, refer Figure 7, will reduce the work done will be obtain or higher energy dissipation is expected. Since a continuous shearing (tends to infinity) will lead to more and more reduction in work done and eventually a strong discontinuity will emerge in a form of slip line.

\subsection{ORIENTATION OF SHEAR BAND}

There has been three different well recognized solutions are proposed; Coulomb solution, Roscoe (1970) and Arthur et al. (1977) solutions, which has been often used to determine shear band orientation. However, it is not clear which one is most acceptable and also it is yet to make a common agreement between experimental and numerical results (Vardoulakis, 1980; Desrus, 1984).

Let us consider a homogeneous plane strain material uniformly stressed up to failure. Onset of localization orientation of shear band $(\theta)$ can be defined as: Mohr-Coulomb solution

$$
\theta_{\mathrm{MC}}= \pm\left(\frac{\pi}{4}+\frac{\phi}{2}\right)
$$

Roscoe solution

$$
\theta_{\mathrm{R}}= \pm\left(\frac{\pi}{4}+\frac{\psi}{2}\right)
$$

Arthur/Vardoulakis solution

$$
\theta_{\mathrm{V} / \mathrm{A}}= \pm\left(\frac{\pi}{4}+\frac{\phi}{4}+\frac{\psi}{4}\right)
$$




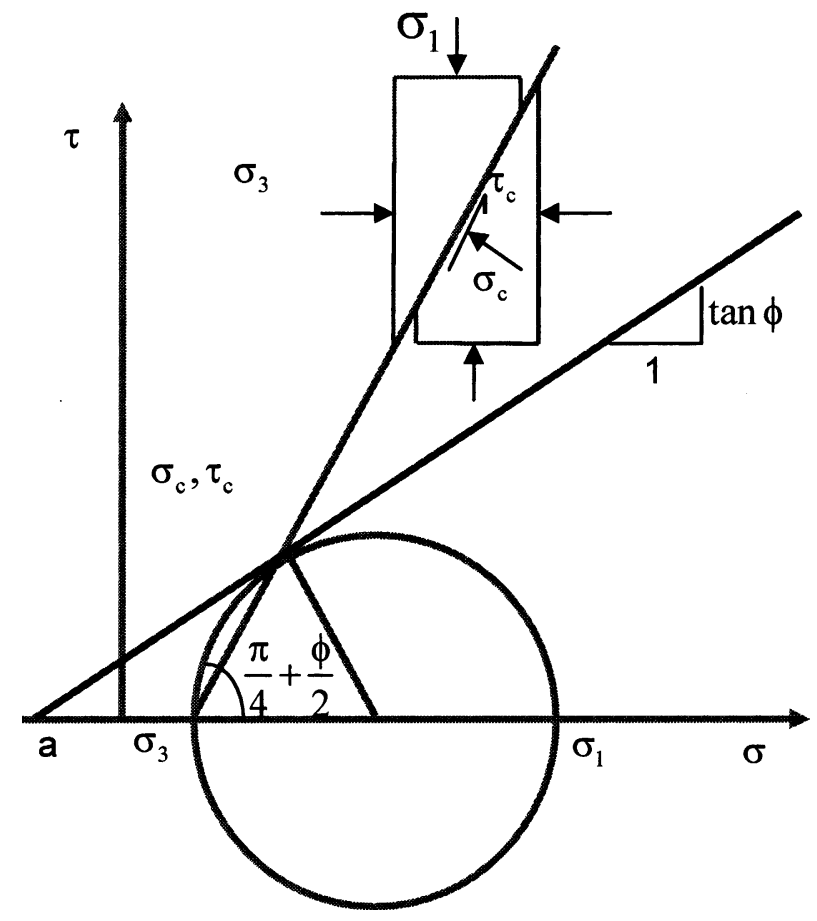

Figure 8. Mohr circle for stresses.

Mohr-Coulomb solution use hypothesis that the rupture planes are parallel to the planes subjected to the principal stress combination; however the Roscoe solution is application to kinematically admissible body. The later one has been more widely accepted by the researcher due to the fact that shear band goes under a continuous deformation and also a kinematics equilibrium condition has to satisfy to obtain bifurcation condition. However, none of these equations guaranteed that shear band will actually follow the same angle while propagating. These solutions are only valid at the point of emergence of shear band and critical propagation angle will change as a function of time and distance.

\section{Strain Localization in Elasto-Plastic Body}

Assuming a usual small strain theory and considering a representative element of an elasto-plastic, strain softening material. The total strain rate can be resolve in reversible and irreversible part.

$$
\boldsymbol{\varepsilon}=\boldsymbol{\varepsilon}^{\mathrm{e}}+\boldsymbol{\varepsilon}^{\mathrm{p}}
$$

Let us consider a regular element with embedded shear band of thickness $t_{\mathrm{sb}}$, inclined at angle $\theta$ from global reference axis XY. Onset of localization, only shear band will 
experience the plastic strain and rest of the body will be elastically unloaded. Figure 9 represents a separate elastic and plastic strain in element.

Considering a plastic flow in local coordinates $(n, t)$ a cumulative strain within shear band can be specified as equation (18).

$$
\begin{aligned}
& {\left[\begin{array}{c}
\mathrm{d} \varepsilon_{t} \\
\mathrm{~d} \varepsilon_{n} \\
\mathrm{~d} \gamma_{n t}
\end{array}\right]=\left[\begin{array}{c}
\mathrm{d} \varepsilon_{t}^{\mathrm{e}} \\
\mathrm{d} \varepsilon_{n}^{\mathrm{e}} \\
\mathrm{d} \gamma_{n t}^{e}
\end{array}\right]+\left[\begin{array}{c}
\mathrm{d} \varepsilon_{s}^{\mathrm{p}} \\
\mathrm{d} \varepsilon_{n}^{\mathrm{p}} \\
\mathrm{d} \gamma_{n t}^{\mathrm{p}}
\end{array}\right]=\left[\begin{array}{c}
\frac{\partial u_{t}}{\partial t} \\
\frac{\partial u_{n}}{\partial n} \\
\frac{\partial u_{n}}{\partial t}+\frac{\partial u_{t}}{\partial n}
\end{array}\right]} \\
& \mathrm{d} \boldsymbol{\varepsilon}^{\mathrm{e}}=\mathbf{C}^{-1} \mathrm{~d} \boldsymbol{\sigma} \\
& \left\{\begin{array}{c}
\mathrm{d} \varepsilon_{n}^{\mathrm{e}} \\
\mathrm{d} \varepsilon_{t}^{\mathrm{e}} \\
\mathrm{d} \gamma_{n t}^{\mathrm{e}}
\end{array}\right\}=\frac{1}{G}\left[\begin{array}{lll}
\frac{3 K+4 G}{12 K+4 G} & \frac{-3 K+2 G}{12 K+4 G} & 0 \\
& \frac{3 K+4 G}{12 K+4 G} & 0 \\
\mathrm{SYM} & & 1
\end{array}\right]\left\{\begin{array}{c}
\mathrm{d} \sigma_{n} \\
\mathrm{~d} \sigma_{t} \\
\mathrm{~d} \tau
\end{array}\right\}
\end{aligned}
$$

And assuming an associated flow rule incremental plastic strain can be written as;

$$
\mathrm{d} \varepsilon^{\mathrm{p}}=\frac{\boldsymbol{1}}{\boldsymbol{A}} \frac{\partial \boldsymbol{f}^{\mathrm{T}}}{\partial \boldsymbol{\sigma}} \frac{\partial \boldsymbol{f}}{\partial \boldsymbol{\sigma}} \mathrm{d} \boldsymbol{\sigma}
$$

Here $A$ is softening modulus;

$$
\begin{aligned}
& \left\{\begin{array}{l}
\mathrm{d} \varepsilon_{n}^{\mathrm{p}} \\
\mathrm{d} \varepsilon_{t}^{\mathrm{p}} \\
\mathrm{d} \gamma^{\mathrm{p}}
\end{array}\right\}=\frac{1}{A}\left[\begin{array}{ccc}
\left(\frac{\partial f}{\partial \sigma_{n}}\right)^{2} & 0 & \frac{\partial f}{\partial \sigma_{n}} \frac{\partial f}{\partial \tau} \\
0 & 0 & 0 \\
\frac{\partial f}{\partial \sigma_{n}} \partial \frac{\partial f}{\partial \tau} & 0 & \left(\frac{\partial f}{\partial \tau}\right)^{2}
\end{array}\right]\left\{\begin{array}{c}
\mathrm{d} \sigma_{n} \\
\mathrm{~d} \sigma_{t} \\
\mathrm{~d} \tau
\end{array}\right\} \\
& \mathrm{d} \varepsilon=\left[\mathbf{D}^{-1}\right] \mathrm{d} \boldsymbol{\sigma} \\
& \mathbf{D}=\left\{\mathbf{C}^{-1}+\frac{1}{\mathbf{A}} \frac{\partial f}{\partial \boldsymbol{\sigma}} \frac{\partial f^{\mathrm{T}}}{\partial \boldsymbol{\sigma}}\right\}
\end{aligned}
$$

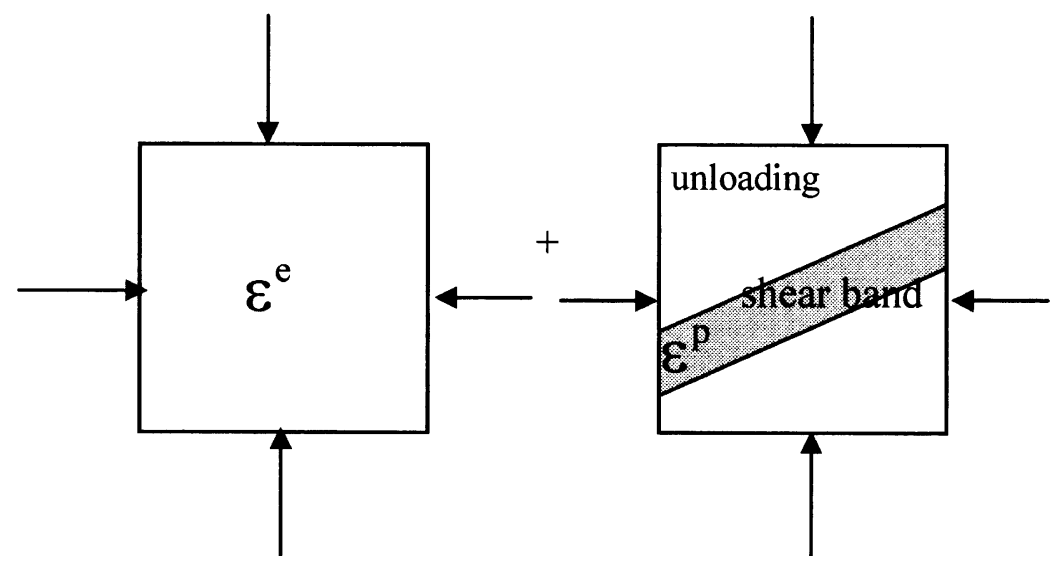

Figure 9. Strains in infinite body. 
Equation 21 can also be written as;

$$
\begin{aligned}
& \mathrm{d} \boldsymbol{\sigma}=[\mathbf{D}] \mathrm{d} \boldsymbol{\varepsilon} \\
& \mathbf{D}=\left\{\mathbf{C}^{-1}+\frac{1}{\mathbf{A}} \frac{\partial f}{\partial \boldsymbol{\sigma}} \frac{\partial f^{\mathrm{T}}}{\partial \boldsymbol{\sigma}}\right\}^{-1} \\
& \left\{\begin{array}{c}
\mathrm{d} \sigma_{n} \\
\mathrm{~d} \sigma_{t} \\
\mathrm{~d} \tau
\end{array}\right\}\left[\begin{array}{lll}
D_{11} & D_{12} & D_{13} \\
D_{21} & D_{22} & D_{23} \\
D_{31} & D_{32} & D_{33}
\end{array}\right]\left\{\begin{array}{c}
\mathrm{d} \varepsilon_{n} \\
\mathrm{~d} \varepsilon_{t} \\
\mathrm{~d} \gamma
\end{array}\right\}
\end{aligned}
$$

The tangential stiffness matrix $[\mathrm{D}]$ or $[\mathrm{D}]_{G}$ referred to the local co-ordinates $(n, t)$, transforming this matrix to the global co-ordinate;

$$
[\mathbf{D}]_{G}=[\mathbf{T}]^{\mathrm{T}}[\mathbf{D}]_{L}[\mathbf{T}]
$$

where

$$
[\mathbf{T}]=\left[\begin{array}{ccc}
\cos ^{2} \theta^{\prime} & \sin ^{2} \theta^{\prime} & \sin \theta^{\prime} \cos \theta^{\prime} \\
\sin ^{2} \theta^{\prime} & \cos ^{2} \theta^{\prime} & -\sin \theta^{\prime} \cos \theta^{\prime} \\
-2 \sin \theta^{\prime} \cos \theta^{\prime} & 2 \sin \theta^{\prime} \cos \theta^{\prime} & \cos ^{2} \theta^{\prime}-\sin ^{2} \theta^{\prime}
\end{array}\right]
$$

$\theta^{\prime}$ need not be similar to $\theta$, measured with respect to a local coordinates.

Component $D_{33}$, represents the tangential shear modulus and a shear band may develop when it is equal to zero. Jostad and Andresen (2004) reported that the shear band formation may be prevented due to change in $\sigma_{n}$. However, $D_{33}$ close to zero would reduce the $\sigma_{n}$ increase at the front of propagating shear band.

\section{Experimental Investigation of Strain Localization in Norwegian Quick Clay}

Numerous efforts have been made to find thickness of shear band experimentally. It is worth to mention contribution from Viggiani et al. (2004) on X-ray micro tomography, Figure 10, for studying localized deformation in fine-graded geomaterials under triaxial compression and microstructural analysis of strain localization in clay (Hicher, Wahyudi and Tessier, 1994) etc.

Typical thickness of shear band in clays given in literature is in the variation from $10 \mu \mathrm{m}$ to $20 \mathrm{~mm}$ (Moore and Rowe, 1988). Pore pressure measurements inside a triaxial sample are also conducted by using probes (Saada et al., 1994).

Determination of localized zone in Norwegian quick clay has always been challenging due to difficulties associated while handling. Such type of clay is very sensitive in nature and easily liquefiable due to collapse of mineral structure. By definition, Norwegian quick clay has a remolded shear strength, $\mathrm{s}_{r}<0.5 \mathrm{kN} / \mathrm{m}^{2}$ and a sensitivity, $\mathrm{S}_{t}>30$. The content of sodium chloride in normal marine clay is about $3.5 \%$. When sodium chloride content is reduced to less than $0.5 \%$, quick clay forms. Norwegian quick clay is highly meta-stable clay due it its card house grain structure, refer Figure 11. A small disturbance can be result a collapse in clay. Quick clay has 


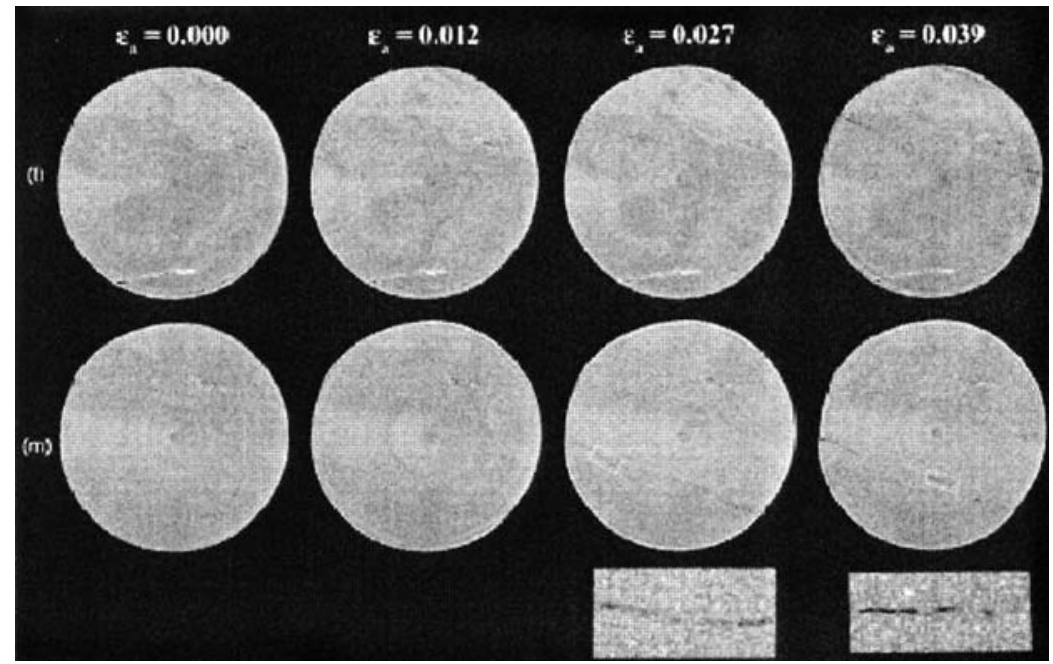

Figure 10. Strain localization in clay rock after Viggiani et al. (2004).

higher water content than its liquid limit, as shown in Figure 12. In past, enormous amount of research has been done to understand the behaviour of Norwegian quick clay. Some of the classical work done by Bjerrum (1954, 1955, 1967), Bjerrum and Landva (1966) can be referred.

A Consolidated undrained (CU) test is performed to unveil the behaviour of Norwegian quick clay. A standard $54 \mathrm{~mm}$ diameter and $10 \mathrm{~mm}$ high sample was chosen and rate of shear was $0.05 \mathrm{~mm} / \mathrm{min}$, From Figure 13, a clear strain softening response and brittle failure can be noted i.e., a rapid decrease in shear resistance after touching yield surface.

In order to investigate localization authors (2005) have presented a set of unconfined compression test at different strain rates. Instrumental set up is depicted in Figure 14.

A simple methodology was adopted to scan shear localization using a video extensometer. A series of small dots were imprint, see Figure 15, on specimen surface
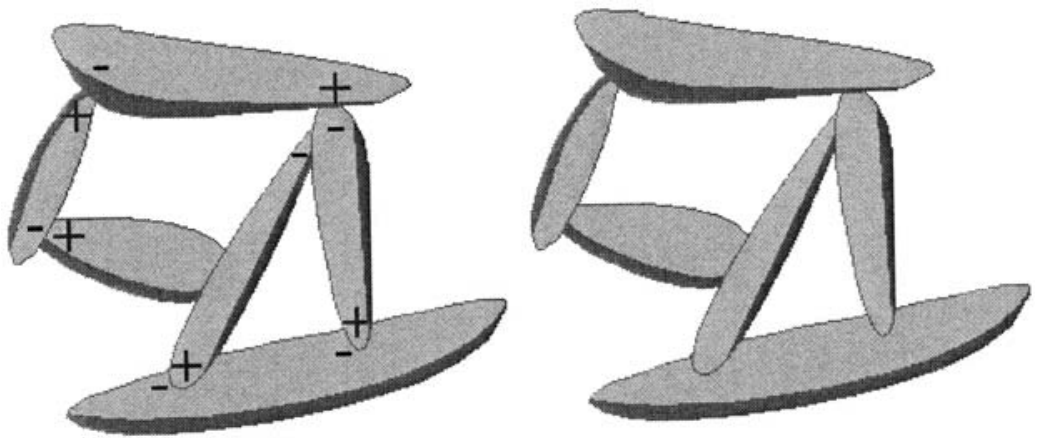

Figure 11. Sketch of normal marine clay (left) and quick clay (right) on a micro structural level. 


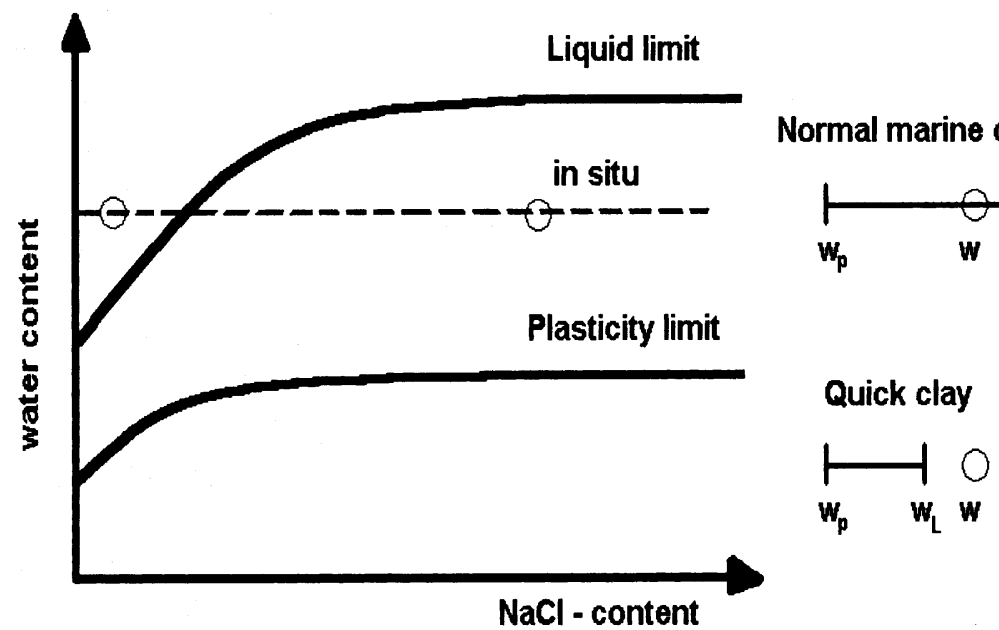

Figure 12. Water content versus salt content.

and traced throughout the test duration. Video extensometer helped in gathering sets of deformation tensor for each dots.

Onset of localization, a microscopic observation is performed, which concludes that shear band thickness is far below than $1 \mathrm{~mm}$, in Norwegian quick clay as shown in Figure 16. A series of test were performed and most of the sample had localization in a form of strong discontinuity i.e. slip surface. Also the orientation of shear band was approximately 37 degrees.

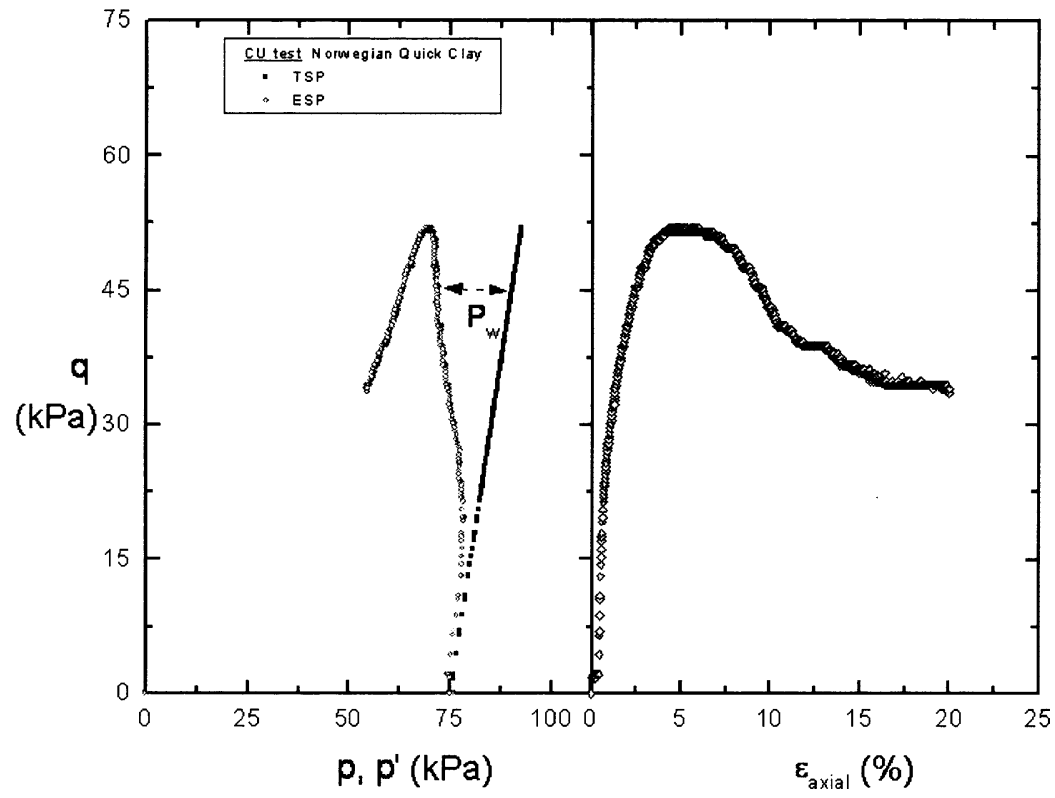

Figure 13. Consolidated undrained test in Norwegian quick clay. 

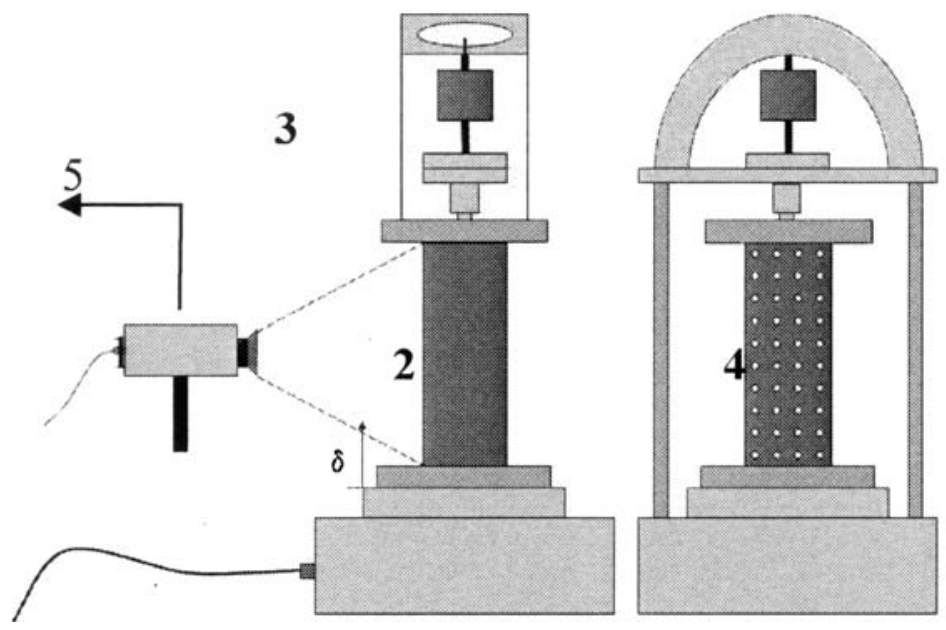

Figure 14. Instrumental set up 1: Video extensometer; 2: sample; 3: Uniaxial device; 4: sample with markers (dots); 5: to data logger.

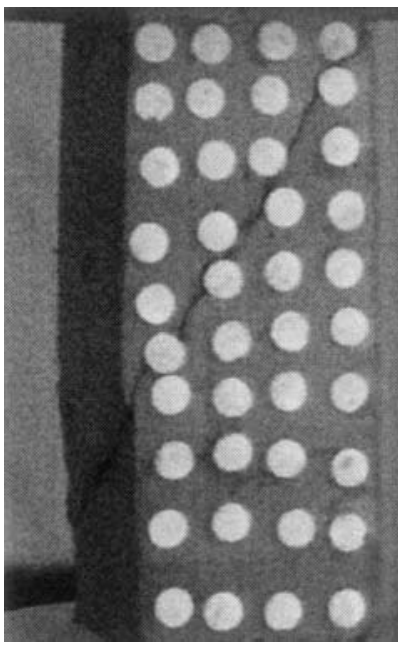

Figure 15. Specimens after localization.

Figure 17 depicts the growth of incremental shear strain during the test. At the beginning of test, when specimen behaves as an elastic body has uniform shear strain. However, on set of localization, a distinct shear zone emerges which contains all plastic shear strain and rest of the body undergone for elastic unloading. 


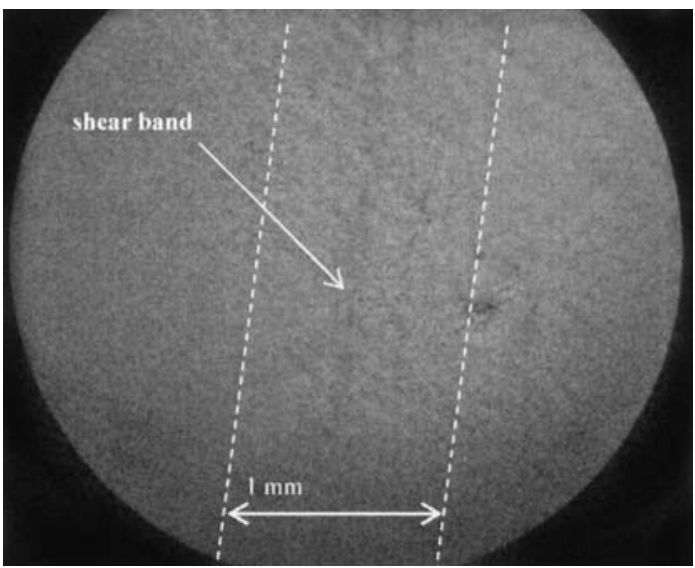

Figure 16. Microscopic view of shear band in failure plane, after Grimstad et al. (2005).

(a)

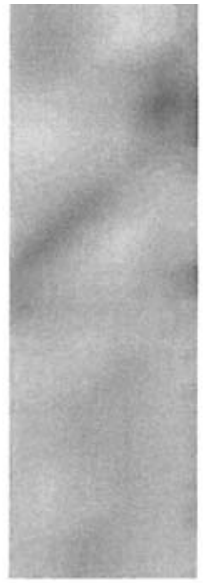

Uniform deformation (b)

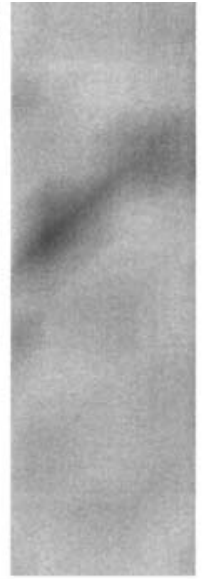

on set of localization (c)

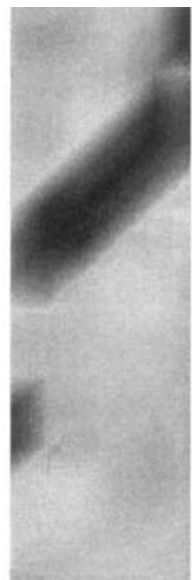

complete growth of shear band

Figure 17. Incremental shear strain distribution plots at different strain level.

\section{Conclusions}

In this paper, classical stability criteria and localization theory is highlight. A summery of shear band analysis using bifurcation theory can be concluded as;

(a) The shear band criterion is necessary but not a guaranteed that shear band will actually emerge.

(b) Orientation of shear band is not unique.

(c) Thickness of shear band left undetermined.

(d) Coulomb and Roscoe solution are lower and upper bound for shear band respectively. 
(e) Bifurcation Theory lacks an internal length parameter. Hence regularization technique must be incorporated in order to obtain a finite thickness of shear band

Finite element simulation is presented, in order to understand the contracting behaviour of sensitive material. Yielding will occur due to reduction in shear resistance due to excess pore pressure developed inside band. However, to obtain and simulate shear band in finite element code either embedded discontinuity, imperfection or irregular boundary condition has to be incorporated.

In this paper, the thickness of shear band is studied experimentally by particle tracking and a numerical algorithm was developing to identify regions of concentrated shear strains and regions of elastic unloading. The experimental observation indicates that the thickness of shear band is quite lower than even $1 \mathrm{~mm}$ i.e. in few microns. However, it is believed that more refined and sophisticated study in biaxial will help in making concrete conclusion.

In sort, here effort was made to acknowledge all relevant theories and limitation associated with strain softening in sensitive clay with the help of finite element analysis and experimental evidence. However, present study does not deal with regularization methods but it is interesting to mention that most of these methods work well for granular materials not for clays.

\section{Acknowledgement}

International Centre for Geohazards (ICG), Norway is gratefully acknowledged for their support and supervision. The Geotechnical division, Norwegian University of Science and Technology, NTNU, is acknowledging with utmost respect for financial support.

\section{References}

Andresen, L. and Jostad, H.P. (2002) A constitutive model for anisotropic and strain-softening clay, In Proceedings of the Numerical Models in Geomechanics - NUMOG VIII, Rome, Italy, pp. 581-585.

Arthur, J.F.R., Dunstan, T., Assadi, Q.A.J. and Assadi, A. (1977) Plastic deformation and failure in granular material, Geotechnique, pp. 53-74.

Bardet, J.P. (1990) A comprehensive review of strain localization in elastoplastic soils, Computers and Geotechnics, 10, 163-188.

Benallal, A., Billardon, R. and Geymonat, G. (1989) Some methamatical aspects of the damage softening rate problem Cracking and Damage, Elsevier, Amsterdam, pp. 247-258.

Bjerrum, L. and Landva, A. (1966) Direct simple shear test on a Norwegian quick clay, Geotechnique, 16(1), 1-20.

Bjerrum, L. (1954) Geotechnlcal properties of Norwegian marine clays, Geotechnique, 3(21), 49-69.

Bjerrum, L. (1955) Stability of natural slopes in quick clay, Geotechnique, 5(1), 101-119.

Bjerrum, L. (1967) Seventh Rankine lecture: Engineering geology of Norwegian normally consolidated marine clays as related to settlement of buildings, Geotechnique, 17(2), 81-118.

de Brost, R., Sluys, L.J., Mulhaus, H.B. and Pamin, J. (1993) Fundamental issues in finite element analyses of localization of deformation, Engineering and Computer, 10, 99-121. 
Desrus, J. (1984) La localization de la dé formation dans les milieuz granularis, Théses de doctorat d'état, Grenoble.

Grimstad, G., Thakur, V. and Nordal, S. (2005) Experimental observation on formation and propagation of shear zone in norwegian quick clay, 11th International conference and field trip on landslides, Trondheim, Norway.

Hadamard, J. (1903) Lecons sur la propagation des ondes et les équations de I' hydrodynamique, Librarie scientifique, A Hermann, Paris.

Hill, J. (1962) Accelaration waves in solids, Journal of Mech. Physics of Solids, 10, 1-16.

Høeg, K. (1972) Finite element analysis of strain softening clay, Journal of Soil Mech. and Foundation Engineering, ASCE, 98(sm 1), 43-58.

Jostad, H.P. and Andresen, L. (2004) Modelling of shear band propagation in clays using interface elements with finite thickness NUMOG, Canada.

Jostad, H.P. (1993) Bifurcation analysis of friction materials, Trondheim, Norway. $\mathrm{Ph} \mathrm{D}$ thesis, NTH, Norges TekniskE Høgskole.

Koiter, T.W. (1960) General Theorems for Elastic-Plastic Solids, In: Sneddon J.N. and Hill R. (eds.). Progress in Solid Mechanics 1, North-Holland, Amsterdam, pp. 165-221.

Mandel, J. (1964) Condition de stabilite' et postulate de Drucker, IUTAM Symposium on Rheology and Soil Mechanics, Grenoble, pp. 58-68.

Morgenstern, N.R. and Tschalenko, J.S. (1967) Microscopic structures in kaolin subjected to direct shear, Geotechnique, 17, 309-328.

Muhlhaus, H.B. and Vardoulakis, I. (1987) The thickness of shear band in granular materials, Geotechnique, 37, 271-283.

Pietrusczak, and Mroz, (1981) Finite element analysis of deformation of strain softening materials, International Nour. Num. Methods in Engineering, 17, 327-334.

Rice, J.R. (1976) The localization of plastic deformation, In Proceedings 14th Int. Congress on Theoretical and Applied Mechanics, Delft, (edited by W.T. Koiter), Vol 1, pp. 207-220.

Roscoe, K.H (1970) The influence of strain in soil mechanics, Geotechnique, 20(2), 129-170.

Rudnicki, J.W. and Rice, J.R. (1975) Conditions for the localization of the deformation in pressure-sensitive dilatant material, Journal of Mech. Physics of Solids, 23, 371-394.

Thakur, V. Jostad, H.P., Nordal, S. and Andresen, L. (2005) Kinematics of shear zone deformation in Norwegian quick clay, 7th IWBIDG, Chania, Greece, June 13-16.

Thakur, V. and Jostad, H.P. (2005) Creep coupled strain softening model for sensitive clays, In 2nd International Workshop for Young Doctors in Geomechanics, WHYDOC, Paris, France, November 23-25.

Thakur, V., Nordal, S., Jostad, H.P. and Andresen, L. (2005) Generation dissipation of pore water during shear banding in sensitive clay, 11th Conference of IACMAG, Turin, Italy, Volume 4.

Thakur, V. and Nordal, S. (2005) Rate dependent elasto plastic deformation of shear band in sensitive clays, Electronic Journal of Geotechnical Engineering, edition September, bundle F.

Thomas, T. (1961) Plastic Flow and Fracture in Solids Academic press, New york.

Vardoulakis, I. (1980) Shear band inclination and shear modulus of sand in biaxial tests, International Journal of Num. Analy. Methods in Geomechanics, 4, 103-119.

Vardoulakis, I. (2002) Dynamic thermo-poro-mechanical analysis of catastrophic landslides, Géotechnique, 52(3), 157-171.

Vardoulakis, I. and Aifantis, E.C. (1991) A gradient flow theory of plasticity for granular materials, Acta Mech., 87, 197-217.

Vermeer, P.A. and Brinkgreve, R.B.J. (1994) A new effective non-local strain measure for softening plasticity, In Proc. 3rd International Workshop on Localization and Bifurcation Theory for Soils and Rocks, Grenoble, France, pp. 89-100. 